\title{
Impact resistance of steel materials to ballistic ejecta and shelter development using steel deck plates
}

\author{
Hiroyuki Yamada1*, Kohei Tateyama², Shino Naruke ${ }^{3}$, Hisashi Sasaki ${ }^{3}$, Shinichi Torigata ${ }^{4}$, Ryo Honda ${ }^{5}$, \\ Tomohiro Kubo ${ }^{5}$, Mitsuhiro Yoshimoto ${ }^{5}$ and Toshitsugu Fujii ${ }^{5}$
}

\begin{abstract}
The destruction caused by ballistic ejecta from the phreatic eruptions of Mt. Ontake in 2014 and Mt. KusatsuShirane (Mt. Moto-Shirane) in 2018 in Japan, which resulted in numerous casualties, highlighted the need for better evacuation facilities. In response, some mountain huts were reinforced with aramid fabric to convert them into shelters. However, a number of decisions must be made when working to increase the number of shelters, which depend on the location where they are to be built. In this study, we propose a method of using high-strength steel to reinforce wooden buildings for use as shelters. More specifically, assuming that ballistic ejecta has an impact energy of $9 \mathrm{~kJ}$ or more, as in previous studies, we developed a method that utilizes SUS304 and SS400 unprocessed steel plates based on existing impact test data. We found that SUS304 is particularly suitable for use as a reinforcing material because it has excellent impact energy absorption characteristics due to its high ductility as well as excellent corrosion resistance. With the aim of increasing the structural strength of steel shelters, we also conducted an impact test on a shelter fabricated from SS400 deck plates (i.e., steel with improved flexural strength provided by work-hardened trapezoidal corrugated plates). The results show that the shelter could withstand impact with an energy of $13.5 \mathrm{~kJ}$ (2.66 kg of simulated ballistic ejecta at $101 \mathrm{~m} / \mathrm{s}$ on impact). In addition, from the result of the impact test using the roof-simulating structure, it was confirmed the impact absorption energy is further increased when artificial pumice as an additional protective layer is installed on this structure. Observations of the shelter after the impact test show that there is still some allowance for deformation caused by projectile impact, which means that the proposed steel shelter holds promise, not only structurally, but also from the aspects of transportation and assembly. Hence, the usefulness of shelters that use steel was shown experimentally. However, shelter construction should be suitable for the target environment.
\end{abstract}

Keywords: Impact, Ballistic ejecta, Phreatic eruption, Impact-resistant design, Stainless steel, Trapezoidal corrugated plate

\section{Introduction}

The phreatic eruption of Mt. Ontake, which is located along the border of Gifu and Nagano Prefectures in Japan, that occurred on September 27, 2014, killed

\footnotetext{
* Correspondence: ymda@nda.ac.jp

'Department of Mechanical Engineering, National Defense Academy,

1-10-20, Hashirimizu, Yokosuka, Kanagawa 239-8686, Japan

Full list of author information is available at the end of the article
}

numerous hikers close to the summit (58 people died and 5 people are missing). The main cause of death was injury due to volcanic blocks and lapilli (hereafter collectively referred to as ballistic ejecta) (Oikawa et al. 2015; Kaneko et al. 2016; Oikawa et al. 2016). In the phreatic eruption of Mt. Kusatsu-Shirane (Mt. MotoShirane) in Gunma Prefecture on January 23, 2018, ballistic ejecta directly struck and killed one Japan Ground

(c) The Author(s). 2021 Open Access This article is licensed under a Creative Commons Attribution 4.0 International License, which permits use, sharing, adaptation, distribution and reproduction in any medium or format, as long as you give appropriate credit to the original author(s) and the source, provide a link to the Creative Commons licence, and indicate if changes were made. The images or other third party material in this article are included in the article's Creative Commons licence, unless indicated otherwise in a credit line to the material. If material is not included in the article's Creative Commons licence and your intended use is not permitted by statutory regulation or exceeds the permitted use, you will need to obtain permission directly from the copyright holder. To view a copy of this licence, visit http://creativecommons.org/licenses/by/4.0/ The Creative Commons Public Domain Dedication waiver (http://creativecommons.org/publicdomain/zero/1.0/) applies to the data made available in this article, unless otherwise stated in a credit line to the data. 
Self-Defense Force member during training (Terada et al. 2018; Yoshimoto et al. 2018). The fatal injuries caused by ballistic ejecta impact in recent years have highlighted the difficulties of coping with volcanic hazards, especially those caused by phreatic eruptions. Phreatic eruptions can occur unpredictably and suddenly, which is extremely dangerous for hikers. For volcanoes, the most effective safety measures are the designation of restricted areas and hazard warnings. However, in Japan, where scenic volcanoes are major tourist destinations, the key challenge is to devise measures against sudden unexpected phreatic eruptions. The development of technology that can mitigate ballistic ejecta impact damage is thus a pressing issue. A previous numerical simulation of the Mt. Ontake eruption suggests that ballistic ejecta $200 \mathrm{~mm}$ in diameter were ejected at a velocity of $145-185 \mathrm{~m} / \mathrm{s}$ (Tsunematsu et al. 2016). With an average velocity at impact of $83-85 \mathrm{~m} / \mathrm{s}$, such a ballistic would be fatal if it struck a human (Baxter and Gresham 1997). However, most of the ballistic ejecta scattered during the eruption of Mt. Ontake in 2014 were approximately $100 \mathrm{~mm}$ in diameter, as determined by fieldwork surveys taken on August 19 and 20, 2015, in a joint survey of the Japanese Coordinating Committee for Prediction of Volcanic Eruptions (Disaster Management, Cabinet Office 2015a, 2015b). The damage caused by the ballistic ejecta appears to have been primarily caused by ballistics mainly $100 \mathrm{~mm}$ in diameter. The handbook on shelters published by the Disaster Management of the Cabinet Office of Japan, which is described in detail later, was prepared based on the results of this survey. After the handbook was published, Japanese shelters have standards to withstand the impact of ballistic ejecta of 100 $\mathrm{mm}$ in diameter at $83 \mathrm{~m} / \mathrm{s}$.

Phreatic eruptions can produce projectiles over $1 \mathrm{~m}$ diameter (e.g. Fitzgerald et al. 2014). However, in this study, we focus on ballistic ejecta of $100 \mathrm{~mm}$ in diameter reported in the field survey as well as previous studies (Yamada et al. 2018) of the phreatic eruption of Mt. Ontake in 2014.

A large number of people were injured due to ballistic ejecta when Mt. Ontake erupted, mainly because of the high number of hikers on a Saturday during autumn. The absence of shelters and facilities along the mountain trails and at the summit is also believed to have been a factor. There are several mountain huts near the top of Mt. Ontake, and none of the hikers who took refuge within them died (Yoshimoto 2015). This suggests that the huts can be used as emergency shelters during sudden eruptions. However, ballistic ejecta did considerable damage to the huts (e.g., it penetrated the roofs and damaged the walls), so it is fortunate that there were few injuries among the people taking refuge within them (Yoshimoto 2015). If mountain huts are to be designated for use as evacuation facilities, it is essential to improve their impact resistance to ballistic ejecta.

In a previous study, the authors experimentally demonstrated that two layers of an aramid fabric (Toray Kevlar $^{\oplus}$ fabric: FS3300) placed between a waterproof sheet and the roof boards of an existing mountain hut could withstand ballistic ejecta impacts with an energy of about $13 \mathrm{~kJ}$ (mass of $2.66 \mathrm{~kg}$ at $100 \mathrm{~m} / \mathrm{s}(360 \mathrm{~km} / \mathrm{h})$ ) (Yamada et al. 2018). Although it was not possible to continue the experiment until penetration occurred because of the limited capacity of the experimental equipment, the results showed that roofs protected in this manner could withstand very high energy levels. Some of the results were published in the Handbook for Improving Volcanic Shelters (hereafter referred to as the handbook) (Disaster Management Bureau, Cabinet Office 2015a, 2015b). Aramid fabric is lightweight; FS3300 aramid fabric is $0.6 \pm 0.1 \mathrm{~mm}$ thick and weighs $0.45 \mathrm{~kg} /$ $\mathrm{m}^{2}$. Because the fabric can be carried by a person, it is a suitable reinforcement material for high-altitude mountain huts where the only options for transporting heavy objects involve helicopters or other specialized equipment. Furthermore, even if helicopters are used, transportation costs are lower than those for metal or concrete. Although aramid fabrics have to be rigidly fixed using bolts to ensure that they do not come off when impacted by ballistic ejecta, this can be done without heavy equipment.

Table 1 and Fig. 1 show the development status of shelters in Japan as of August 2020 after the publication of the handbook. As shown, many mountain huts and visitor centers have already been reinforced with aramid fabric. In particular, a significant number of aramid fabric reinforcements were performed after the eruption of Mt. Ontake, reflecting the high level of awareness in disaster-affected municipalities. However, considering the 111 active volcanoes in Japan, the spread of aramid fiber fabric reinforcement is still far away. This is due to the problem that aramid fiber fabrics are very expensive and cannot be easily introduced. Therefore, in order to promote the reinforcement of the current mountain huts, it is necessary to study a method that can provide a certain level of reinforcement at a lower cost without requiring high performance up to aramid fiber fabric. In addition, in some cases, aramid fabric was also used in locations easily accessible by heavy equipment. Note that reinforced concrete (RC) and steel structure shelters were also built.

The handbook recommends the installation of RC shelters using arch and box culverts, among others, in places where heavy construction work can be carried out. Numerous studies have reported on the excellent impact resistance of RC shelters to flying and falling objects (e.g., Ito et al. 1991). Hence, even though a specific 
Table 1 Development status of evacuation facilities after publication of the handbook for improving volcanic shelters by the Disaster Management of the Cabinet Office of Japan (as of August 2020). The numbers in the table correspond to those shown in Fig. 1

\begin{tabular}{|c|c|c|c|c|c|}
\hline No. & Volcano name & Facilities & $\begin{array}{l}\text { Structure and reinforcement } \\
\text { method }\end{array}$ & $\begin{array}{l}\text { Distance from } \\
\text { crater }(m)\end{array}$ & Crater used for measurement \\
\hline 1 & Mt. Tokachi-dake & $\begin{array}{l}\text { Emergency evacuation } \\
\text { facility }\end{array}$ & $\begin{array}{l}\text { Reinforced concrete (RC) } \\
\text { construction }\end{array}$ & 3400 & $62-2$ crater \\
\hline 2 & $\begin{array}{l}\text { Mt. Akita- } \\
\text { yakeyama }\end{array}$ & $\begin{array}{l}\text { Mountain hut: } \\
\text { Yakeyama emergency } \\
\text { hut }\end{array}$ & $\begin{array}{l}\text { Wooden building reinforced with } \\
\text { aramid fabric }\end{array}$ & 200 & Onigajyo \\
\hline 3 & Mt. Iwate & $\begin{array}{l}\text { Mountain hut: } \\
\text { Eighth station's } \\
\text { emergency shelter }\end{array}$ & $\begin{array}{l}\text { Wooden building reinforced with } \\
\text { aramid fabric }\end{array}$ & 750 & Omuro crater \\
\hline 4 & Mt. Azuma & Visitor Center & $\begin{array}{l}\text { Steel frame building reinforced } \\
\text { with aramid fabric }\end{array}$ & 700 & Ooana crater \\
\hline 5 & Mt. Nasu & $\begin{array}{l}\text { Mountain hut: } \\
\text { Minenochaya ruins } \\
\text { emergency hut }\end{array}$ & $\begin{array}{l}\text { Wooden building reinforced with } \\
\text { aramid fabric }\end{array}$ & 650 & West side slope of Chausudake \\
\hline 6 & $\begin{array}{l}\text { Mt. Kusatsu- } \\
\text { Shirane }\end{array}$ & $\begin{array}{l}\text { Emergency evacuation } \\
\text { facility }\end{array}$ & RC construction & 1000 & $\begin{array}{l}\text { Near center of crater chain of } 2018 \mathrm{Mt} \\
\text { Moto-shirane eruption }\end{array}$ \\
\hline 7 & $\begin{array}{l}\text { Mt. Niigata- } \\
\text { Yakeyama }\end{array}$ & $\begin{array}{l}\text { Mountain hut: Koyaike } \\
\text { Hutte }\end{array}$ & $\begin{array}{l}\text { Steel frame building reinforced } \\
\text { with aramid fabric }\end{array}$ & 4650 & Summit Crater \\
\hline 8 & $\begin{array}{l}\text { Mt. Tateyama, } \\
\text { Midagahara }\end{array}$ & Mountain hut: Raichoso & $\begin{array}{l}\text { Steel frame building reinforced } \\
\text { with aramid fabric }\end{array}$ & 400 & Jigokudani \\
\hline 9 & Mt. Norikura & $\begin{array}{l}\text { Mountain hut: } \\
\text { Katanokoya }\end{array}$ & $\begin{array}{l}\text { Wooden building reinforced with } \\
\text { aramid fabric }\end{array}$ & 950 & Kengamine \\
\hline \multirow[t]{10}{*}{10} & Mt. Ontake & $\begin{array}{l}\text { Emergency evacuation } \\
\text { facility }\end{array}$ & RC construction & 450 & Near center of 2014 crater chain \\
\hline & & $\begin{array}{l}\text { Emergency evacuation } \\
\text { facility }\end{array}$ & Steel structure & 550 & \\
\hline & & $\begin{array}{l}\text { Mountain hut: Kitosho } \\
\text { (prayer room) }\end{array}$ & $\begin{array}{l}\text { Wooden building reinforced with } \\
\text { aramid fabric }\end{array}$ & 450 & \\
\hline & & $\begin{array}{l}\text { Mountain hut: Ninoike } \\
\text { shinkan }\end{array}$ & & 1000 & \\
\hline & & $\begin{array}{l}\text { Mountain hut: Ninoike } \\
\text { Hutte }\end{array}$ & & 1050 & \\
\hline & & $\begin{array}{l}\text { Mountain hut: Ishimuro } \\
\text { sanso }\end{array}$ & & 1050 & \\
\hline & & $\begin{array}{l}\text { Mountain hut: Gonoike } \\
\text { goya }\end{array}$ & & 2250 & \\
\hline & & $\begin{array}{l}\text { Mountain hut: } \\
\text { Otaki Chojo emergency } \\
\text { hut }\end{array}$ & & 550 & \\
\hline & & $\begin{array}{l}\text { Mountain hut: } \\
\text { Ninth station's } \\
\text { emergency hut }\end{array}$ & & 700 & \\
\hline & & $\begin{array}{l}\text { Mountain hut: } \\
\text { Eighth station's } \\
\text { emergency hut }\end{array}$ & & 1400 & \\
\hline \multirow[t]{2}{*}{11} & Mt. Hakone & $\begin{array}{l}\text { Emergency evacuation } \\
\text { facility }\end{array}$ & $\mathrm{RC}$ construction & 200 & Crater of 2015 eruption \\
\hline & & $\begin{array}{l}\text { Emergency evacuation } \\
\text { facility }\end{array}$ & Steel structure & 400 & \\
\hline 12 & Mt. Kirishima & Visitor Center & $\begin{array}{l}\text { Wooden building reinforced with } \\
\text { aramid fabric }\end{array}$ & 950 & Mountain peak of Mt. lo \\
\hline
\end{tabular}



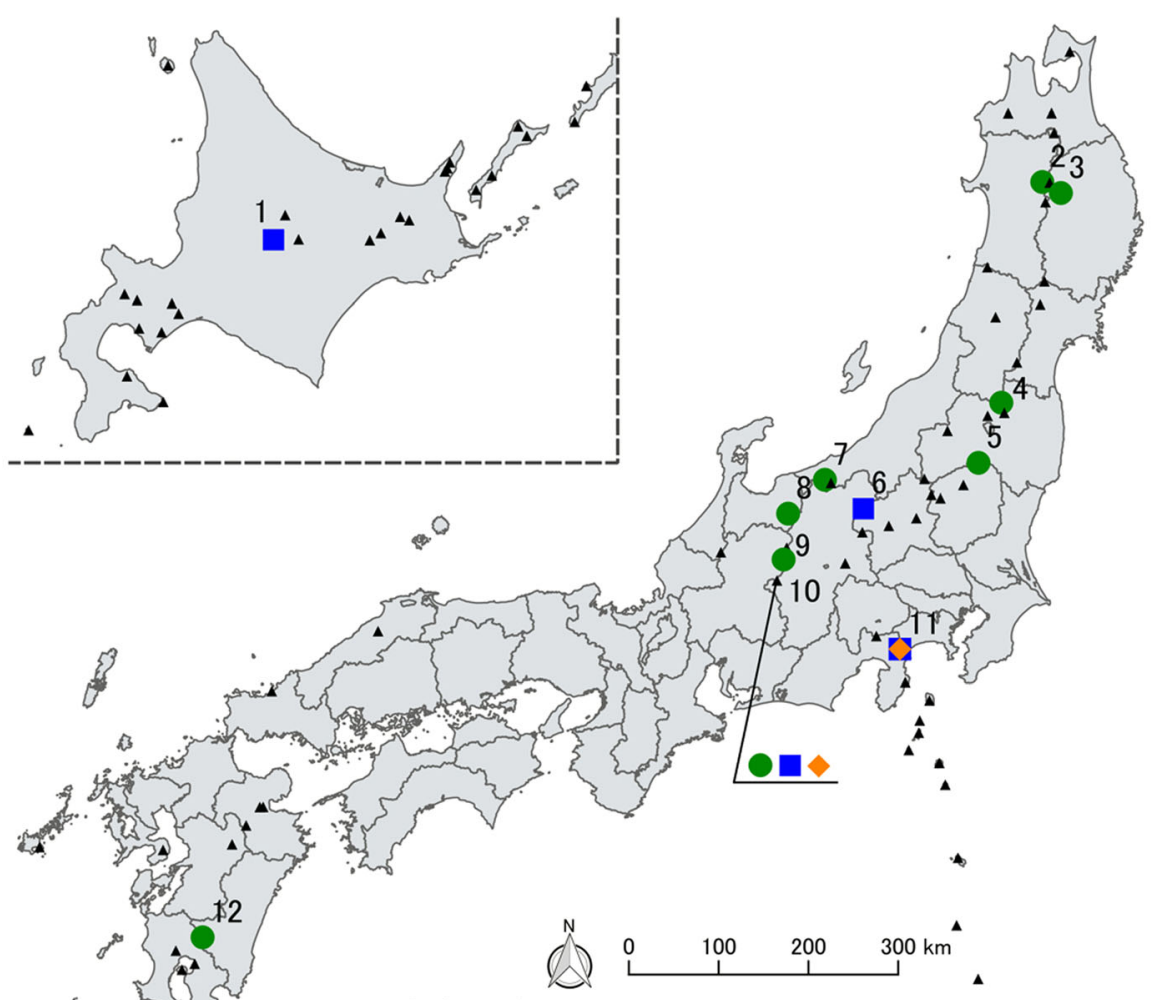

- Active volcano

- Active volcano where reinforcement using aramid fabric is completed (or underway)

$\therefore$.

Active volcano with reinforced concrete shelter installed

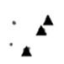

$\checkmark$ Active volcano with steel structure shelter installed

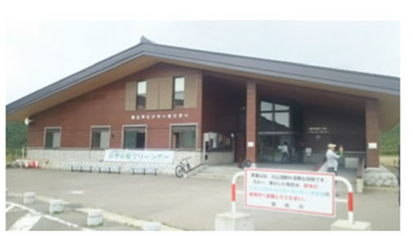

4. Mt. Azuma :

Visitor center with roof reinforced with aramid fabric

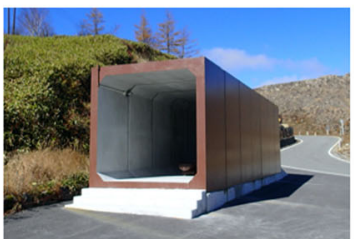

6. Mt. Kusatsu-Shirane : Reinforced concrete shelter

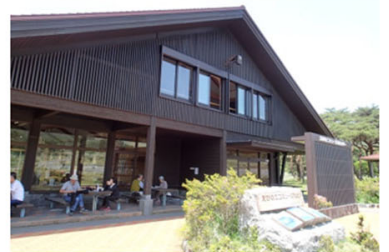

\section{Mt. Kirishima:}

Visitor center with roof reinforced with aramid fabric

Fig. 1 Development status of evacuation facilities after publication of the handbook for improving volcanic shelters by the Disaster Management of the Cabinet Office of Japan (as of August 2020). Details are shown in Table 1

impact resistance to ballistic ejecta from a volcanic eruption has not been clearly specified, many RC shelters have been set up in the vicinity of active volcanoes such as Mt. Aso, Mt. Sakurajima, and Mt. Kirishima in the Kyushu region in Japan (Erfurt-Cooper 2010; Fitzgerald et al. 2017). Williams et al. (2017) recently conducted experiments that simulated ballistic ejecta impacts on RC shelters and provided more realistic safety design guidelines based on empirical reliability. Furthermore, studies have shown that the safety of RC shelters can be increased by reinforcing them with highperformance fabric adhesion (Beppu et al. 2012) to prevent back surface scabbing from occurring during high- speed impacts (Hughes 1984; Ito et al. 1995), which is an issue for RC structures, and by layering them with cushioning materials such as sand, gravel or tephra (Bhatti and Kishi 2010; Bhatti 2015; Yamaguchi et al. 2015; Williams et al. 2019).

Although setting up RC shelters as measures against ballistic ejecta impact seems like a simple solution, the above studies show that the total cost, which include the costs of the RC shelter, installation, and material transportation, can be very high. Additionally, it is not possible to set up such shelters within the ballistic hazard zone ( $<5 \mathrm{~km}$ from the vent) of every volcano. Moreover, it would be difficult to set up RC shelters at World 
Heritage Sites and in National Parks, such as Mt. Fuji, and other areas with landscape restrictions, even if heavy construction could be carried out without incurring high transportation costs. In these cases, the best solution is to reinforce existing mountain huts. An affordable reinforcement material is thus needed. Considering the need for more impact-resistant shelters against ballistic ejecta, we herein report on the development of a reinforcement method for wooden buildings and shelters that is different from conventional methods (Yamada et al. 2018; Yamada et al. 2019).

To provide better evacuation facilities, reinforcement materials that are compatible with the target location must be selected. With this in mind, to increase the available options, we propose the use of easily available and relatively inexpensive steel materials. Temporary shelters made of steel have been installed at construction sites around active volcanoes in Japan, as shown in Fig. 2. Steel shelters are considered optimal for temporary evacuation because they are easy to assemble and disassemble. In addition, as known from the damage to the gondola lift caused by ballistic ejecta impact in Mt. Moto-Shirane eruption (Kanagawa Shimbun 2018), there are also many structures made of steel materials around the active volcanoes. However, we did not find any safety design criteria for their impact resistance to ballistic ejecta. Additionally, to the best of our knowledge, steel shelters to protect against volcanic ballistic ejecta have not been constructed outside Japan. There are no reports that quantitatively discuss the suitability of steel materials for shelters. Therefore, to evaluate the impact resistance of ballistic blocks to steel materials, this study uses the results of impact tests on existing steel materials that the authors had previously conducted (Yamada et al. 2016; Fukui et al. 2017). Due to the effects of volcanic gases such as sulfur dioxide $\left(\mathrm{SO}_{2}\right)$ and hydrogen sulfide $\left(\mathrm{H}_{2} \mathrm{~S}\right)$ in the vicinity of such shelters, we chose stainless steel plates, which have high corrosion resistance, as our first candidate material, and analyzed structural steel plate data to propose a simple mountain hut reinforcement against ballistic ejecta that did not use aramid fabric. Moreover, it is not necessary to rely solely on the strength of the material itself to suppress the bending deformation that occurs at the time of ballistic ejecta impact because steel can be fabricated into different shapes, making it possible to fabricate structures with high flexural strength. For example, the corrugated plate shown in Fig. $2 \mathrm{~b}$ is superior in strength to a flat plate of the same material, and its usage is expected to enhance the structural strength of the shelter. Therefore,
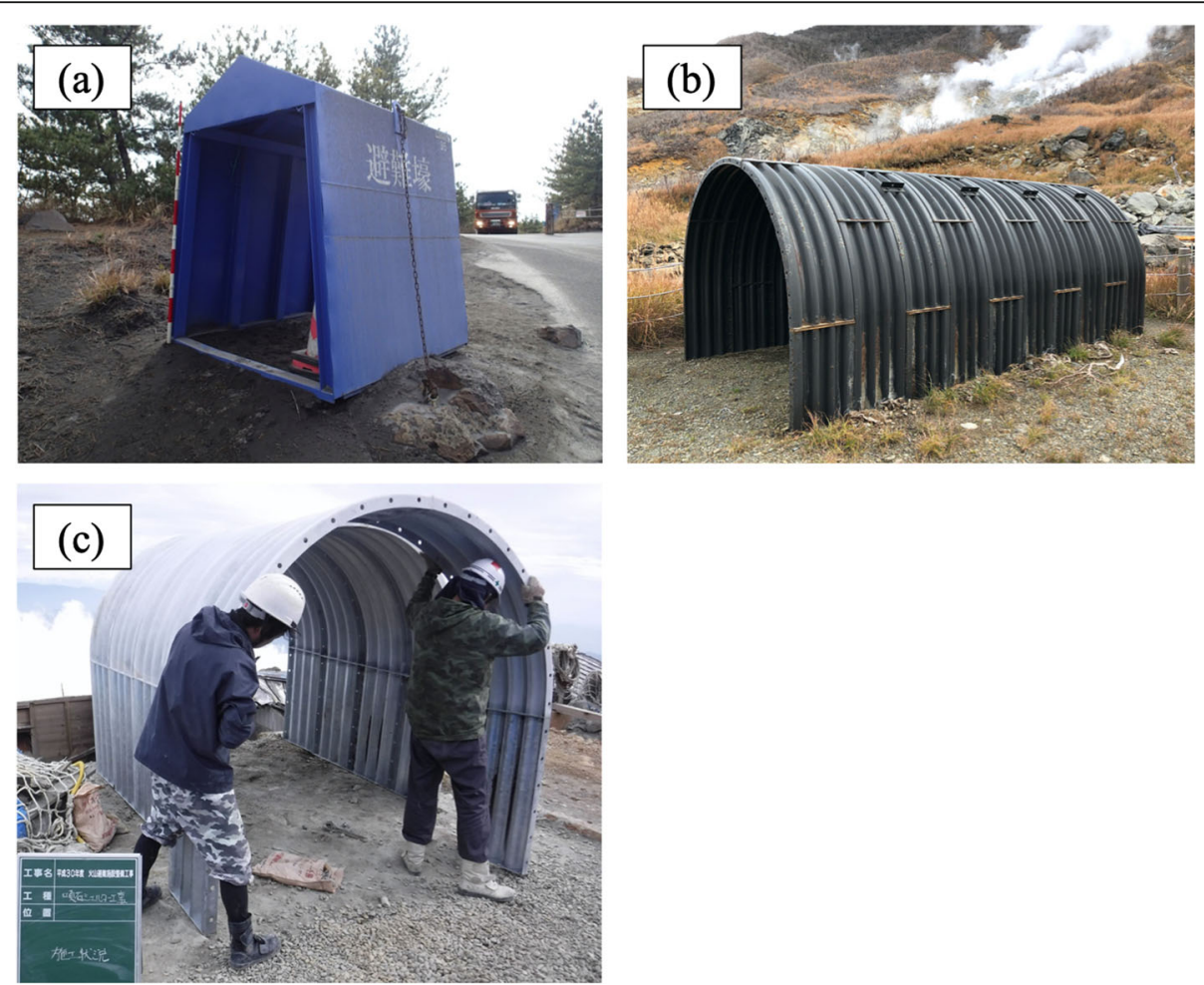

Fig. 2 Examples of temporary shelters that use steel at worksites. a Shelter on Mt. Sakurajima painted dark blue to stand out as an evacuation facility. b Steel shelter (of unknown material) at Hakone Owakudani corresponding to No. 11 in Fig. 1 and Table 1. Unlike the shelter on Mt. Sakurajima, it is fabricated from several corrugated sections. c Assembly of a temporary steel shelter (material: SS330 of JIS G3101) on summit of Mt. Ontake. Photograph taken by Takizawa Koumuten Co., Ltd in 2018. This shelter was installed during working hours 
as a structure with even higher strength, we experimentally studied the applicability of using trapezoidal corrugated deck plates on shelters. In addition, the effect of emplacing pumice on this structure was also examined.

\section{Mountain hut roof reinforcement using steel materials (application of previous study results) Candidate reinforcement materials}

Numerous experimental studies examining the impact of projectiles on steel plates have been conducted (Chiba et al. 1981; Ohte et al. 1981; Børvik et al. 1999; Kpenyigba et al. 2013). The Manual on Design, Construction and Maintenance for Steel Roofing and Wall (MSRW2014) (Japan Metal Roofing Association, Japanese Society of Steel Construction 2014), in which countermeasures against projectiles driven by strong winds impacting steel plates are considered, has recently been published in Japan. Moreover, research on abrasive collision safety for grinding machine covers made of steel (SUS304 and SS400) has also been conducted and the data obtained have been used in proposals of international standards (Yamada et al. 2016; Fukui et al. 2017). These studies show the results of impact tests carried out on steel plates in a wide range of engineering fields, including nuclear, architectural, and mechanical engineering.

Metallic materials installed on active volcanoes often suffer from corrosion caused by volcanic gases. Previous studies that employed experimental conditions simulating actual volcanic environments to examine the extent of volcanic gas corrosion that occurs when volcanic ash adheres to metallic materials have revealed that the amount of volcanic ash affects the extent of volcanic gas corrosion (Izumo et al. 1990; Oze et al. 2014). However, details of how metallic materials are corroded by longterm exposure to low volcanic gas concentrations in environments accessible to hikers and tourists are unknown.

In this study, stainless steel and conventional steel plates, which are in widespread general use, were selected as candidate reinforcing materials for use in resisting ballistic ejecta. For the stainless steel plate, we used SUS304 (which is defined in the Japan Industrial Standards (JIS) as G 4305:2012) because it is in widespread use in Japan. (Note that this material is referred to as 4301-304-00-I in the International Organization for Standardization (ISO) 15,510:2014 standards). The primary chemical composition of SUS304, a typical austenite stainless steel, contains $18 \% \mathrm{Cr}$ and $8 \% \mathrm{Ni}$. Due to its excellent corrosion resistance, ductility, weldability, and strength, it is widely used in engineering, from household goods to nuclear equipment. In this study, we considered SUS304 as our first candidate material because of its superior corrosion resistance compared to that of other steel materials.

For the conventional steel plate, we used rolled steel for general structures SS400 (JIS G 3101:2015), which is widely marketed in Japan because of its many shape and size options as well as its versatility and affordability. The numbers following SS represent the lower limit of tensile strength (maximum stress during a tensile test). For SS400, the tensile strength ranges from 400 to 510 $\mathrm{MPa}$. There are no specifications regarding the detailed chemical composition, such as carbon content. Furthermore, there is no equivalent product for SS400 in ISO 630 for steel materials, although E275A, E275B, E275C, and E275D match its tensile strength. Without surface treatment, the corrosion resistance of SS400 is very poor compared to that of SUS304. Note that the SS400 used in this experiment was not surface-treated.

Figure 3 shows the nominal stress-strain $(\sigma-\varepsilon)$ relationship for SUS304 and SS400 reported in previous studies (Yamada et al. 2016; Fukui et al. 2017). Table 2 shows the chemical composition of SUS304 and SS400. Specimens of these materials were made from the same lot as that used for the plate used for the impact test described later. The data (Yamada et al. 2016; Fukui et al. 2017) are the results of quasi-static tensile tests (strain rate from $10^{-4}$ to $10^{-2} \mathrm{~s}^{-1}$ ) conducted using a commercially universal testing machine (Instron, 5500R) and high strain rate tensile tests (strain rate from approximately $10^{2}$ to $10^{3} \mathrm{~s}^{-1}$ ) conducted using the splitHopkinson pressure bar method (Institute of Space Dynamics, ST-R-5000) (Hopkinson 1914; Kolsky 1949).

For the impact tensile test, complete data (i.e., until fracture) could not be collected due to the limited capacity of the testing apparatus (arrows in Fig. 3). The figure shows that SUS304 is a more highly ductile material with a larger fracture strain than SS400. Moreover, at the early stages of deformation, it can be seen that the flow stress clearly increases as the strain rate increases for both materials, indicating a positive strain rate dependence of material strength. However, for SS400, the flow stress does not increase significantly with increasing strain (i.e., the work-hardening rate is low) at the high strain rate used in the test, which is considered to be close to the strain rate during the impact test. In contrast, the high-strain-rate data for SUS304 shows a work-hardening rate that is similar to that for the quasistatic tensile test, which indicates high flow stress until fracture.

\section{Impact energy of steel materials based on previous results}

As described above, the authors previously reported the results of abrasive (projectile material) impact tests on SUS304 (Fukui et al. 2017) and SS400 (Yamada et al. 

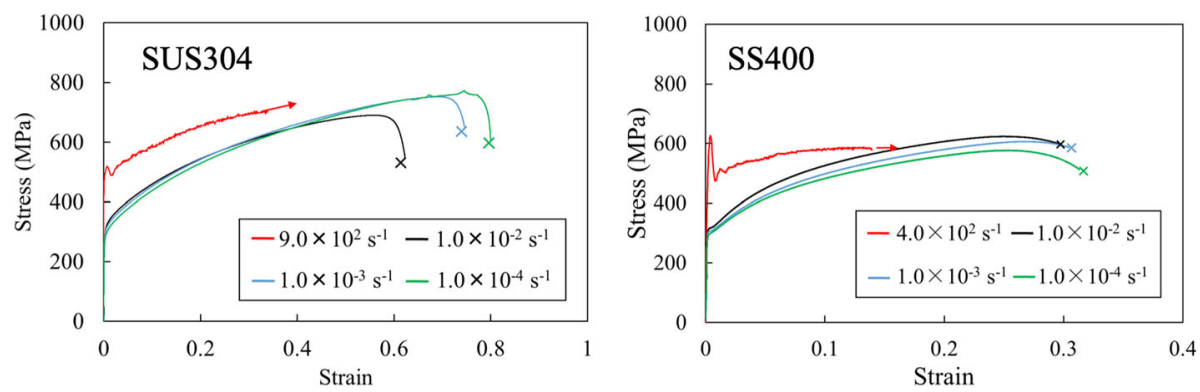

Fig. 3 Nominal stress-strain relationship for SUS304 (Fukui et al. 2017) and SS400 (Yamada et al. 2016). Strain rate from $10^{-4}$ to $10^{-2} \mathrm{~s}^{-1}$ was obtained from quasi-static test; strain rate of $10^{2} \mathrm{~s}^{-1}$ was obtained from high-strain-rate test. Due to the limited capacity of the testing apparatus, the impact test could not be carried out until fracture. Therefore, the curves end with arrows in the figure

2016) in grinding machine cover safety evaluations. These results are from tests carried out using exactly the same abrasive, device, and method as those used in previously reported reinforcement experiments (impact tests) on mountain huts (Yamada et al. 2018). One point where the experimental conditions differ is in the length of the projectile used, which was changed from 170 to $220 \mathrm{~mm}$ (weight: $3.4 \mathrm{~kg}$ ). Nevertheless, in the present study (as in previous experiments), because the impact surface area is the same ( $90 \mathrm{~mm}$ in diameter), the kinetic energy of the projectile could be compared by considering it as impact energy.

Figure 4 shows the relationship between the impact energy and the plate thickness for SUS304 and SS400. In this figure, the point where the steel plate fractures and is penetrated is indicated by $x$, that where the steel plate fractures but is not penetrated through by the projectile (projectile is stuck in the steel plate) is indicated by $\square$, and that where the whole plate undergoes plastic deformation only without fracturing is indicated by $\circ$. Because the data indicated by $\square$ are the critical energy that defines the boundary between fractured and unfractured steel plates, this value is defined as the penetration boundary energy $\left(E_{\mathrm{p}}\right)$. It can be seen that the penetration boundary energy for SUS304 is higher than that for SS400. Impact energy absorption $U\left(\mathrm{~J} / \mathrm{m}^{3}\right)$ can generally be expressed by the following equation.

$$
U=\int \sigma d \varepsilon
$$

Table 2 Main chemical constituents of SUS304 and SS400 (mass\%)

\begin{tabular}{llllllll}
\hline Chemical component & C & Si & Mn & P & S & Ni & Cr \\
\hline SUS304 & 0.06 & 0.57 & 1.03 & 0.03 & 0.00 & 8.07 & 18 \\
SS400 & 0.11 & - & 0.47 & 0.01 & 0.00 & - & - \\
\hline
\end{tabular}

It is evident from the above equation that the impact energy absorption increases as the stress $(\sigma)$ and ductility $(d \varepsilon)$ increase. Consequently, SUS304, which has higher flow stress and higher ductility than those for SS400, shows excellent impact energy absorption.

Based on the impact test results, the relationship between the penetration boundary energy $\left(E_{\mathrm{p}}\right)$ and the plate thickness $(t)$ can be expressed by the following equation for both SUS304 and SS400.

$$
E_{p}=k t^{2}
$$

where $k$ is a material constant. Eq. (2) estimates the energy to be proportional to the square of the plate thickness assuming a rigid perfectly plastic material and considering a model with local bending (hinge) at the outer edge of the impact surface (Yamada et al. 2016).

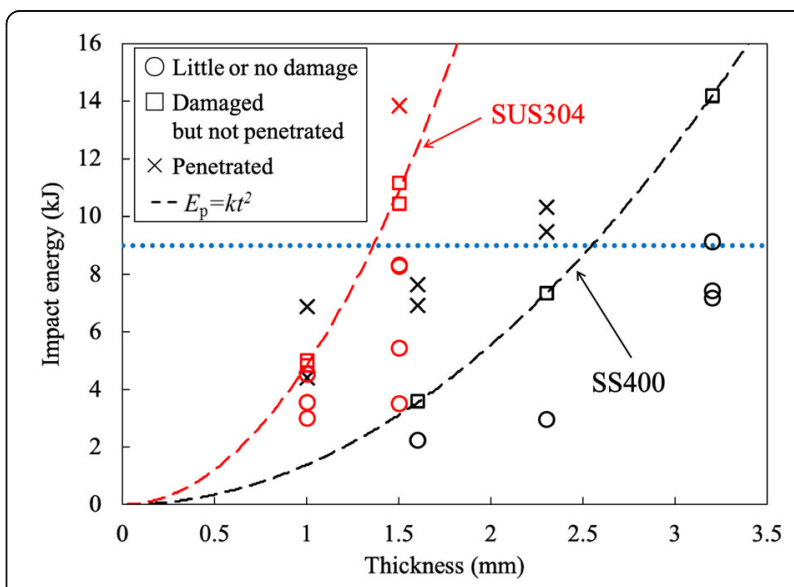

Fig. 4 Relationship between impact energy and plate thickness for SUS304 (Fukui et al. 2017) and SS400 (Yamada et al. 2016). The dashed lines represent the relationship between the penetration boundary energy and the plate thickness. The dotted line indicates the modelled impact energy of $9 \mathrm{~kJ}$ for $128 \mathrm{~mm}$ diameter, spherical ballistic ejecta (2.66 kg at approximately $83 \mathrm{~m} / \mathrm{s}$ on impact) that were ejected during the Mt. Ontake eruption in 2014. As shown, for a given plate thickness, SUS304 is superior to SS400 in terms of impact resistance 
This empirical formula is useful for calculating the penetration boundary energy. The constant $k$ obtained from the experiment for SUS304 and SS400 is 4847 and 1387 $\mathrm{J} / \mathrm{mm}^{2}$, respectively. The value of $k$ is important as it represents the magnitude of the penetration boundary energy.

\section{Comparison of steel plate and aramid fabric}

Table 3 shows a comparison of the results for a steel plate and aramid fabric. We compared the mountain hut reinforcement methods using SUS304, SS400, and aramid fabric (previous study). For a maximum impact energy of the ballistic ejecta of $9 \mathrm{~kJ}$, the thickness of the steel plate calculated using Eq. (2) is $1.36 \mathrm{~mm}$ for SUS304 and $2.55 \mathrm{~mm}$ for SS400. Because there are no standards with these thicknesses, we considered sizes that are generally sold throughout Japan, using $t=1.5$ $\mathrm{mm}\left(E_{\mathrm{p}} \approx 11 \mathrm{~kJ}\right)$ for SUS304 and $t=3.2 \mathrm{~mm}\left(E_{\mathrm{p}} \approx 14 \mathrm{~kJ}\right)$ for SS400. Two layers of aramid fabric are necessary, as discussed in a previous paper (Yamada et al. 2018).

We regarded mass as an important consideration in the transportation and construction necessary for reinforcement. In terms of mass per unit area $\left(\mathrm{kg} / \mathrm{m}^{2}\right)$, SUS304 and SS400 are much heavier than aramid fabric, as shown in Table 3. The construction of mountain huts has to be reconsidered when using steel plates. Furthermore, because SS400 has poor corrosion resistance, the use of stainless steel plates (e.g., SUS304) is recommended. If SS400 is used, it is necessary to apply paint to improve corrosion resistance. However, evaluation of corrosion resistance to volcanic gas is an issue for the future.

If construction cost is taken into consideration, the primary factor is the price of materials. In Japan, reinforcement with SUS304 can be performed at around half the price of that with aramid fabric (rough estimate for $200 \mathrm{~m}^{2}$ of roof, as the price varies depending on the amount of material used). Additionally, taking the construction period into consideration, a large number of work days are required for reroofing when using aramid fabric, whereas SUS304 can be installed in a short period of time because it can be attached on top or installed in lieu of a Galvalume steel plate. Therefore, considering the cost of materials and the construction period, SUS304 may be more affordable than aramid fabric. However, transportation cost is a major factor, and thus the reinforcement operation should be suitable for the target environment. Specifically, SUS304 should be used for locations where construction is easy and cranes can be employed, whereas aramid fabric should be used for locations where construction is difficult, such as on high-altitude volcanoes that would typically require helicopter transport for the materials.

\section{Impact resistance to ballistic ejecta of steel deck plates}

As described above, existing steel shelters, such as those shown in Fig. 2, have questionable safety because they were not made based on ballistic ejecta impact standards. Moreover, using steel plates in plate form does not make full use of steel's work-hardening potential. Accordingly, considering the damage caused by the Mt. Ontake eruption (estimated impact energy of $9 \mathrm{~kJ}$ for the most common, $128 \mathrm{~mm}$ diameter projectiles), we developed a steel shelter for this study that uses deck plates (i.e., steel with improved flexural strength provided by work-hardened trapezoidal corrugated plates). The main objective of this section was to verify the impact resistance of the deck plate material under impact from ballistic ejecta by conducting simulated ballistic ejecta impact experiments. However, it is difficult to process the deck plate of stainless steel due to its high strength (e.g. SUS304), and the processing technology has not been developed yet. Although there is a problem of corrosion resistance, SS400 was used as the material for the deck plate.

\section{Experimental method Simulated ballistic ejecta projectile}

Although the range of natural density of the ballistic block is wide (e.g., Breard et al. 2014), the density of approximately $2400 \mathrm{~kg} / \mathrm{m}^{3}$ was adopted in this study. Similar to a previous study (Yamada et al. 2018), the projectiles were made from a series of 90 -mm-diameter cylindrical abrasives (from white alumina used for grinding with grinding machines) to produce a simulated ballistic ejecta projectile (hereafter referred to as a projectile) with a mass of $2.66 \mathrm{~kg}$ (equivalent to a sphere with a diameter of $128 \mathrm{~mm}$ ). This projectile had hardness comparable to ballistic ejecta.

Table 3 Comparison of results for steel plate (SUS304 and SS400) and aramid fabric

\begin{tabular}{lll}
\hline Material & Condition preventing impact energy of $\mathbf{9} \mathbf{~ J}$ for ballistic ejecta & Mass per unit area $\left(\mathbf{k g} / \mathbf{m}^{\mathbf{2}}\right)$ \\
\hline SUS304 & Thickness of $1.5 \mathrm{~mm}\left(E_{p} \fallingdotseq 11 \mathrm{~kJ}\right)$ & 11.85 \\
SS400 & Thickness of $3.2 \mathrm{~mm}\left(E_{p} \fallingdotseq 14 \mathrm{~kJ}\right)$ & 24.96 \\
Aramid fabric & Two-ply $\left(E_{p}=13 \mathrm{~kJ}\right)$ & Above 0.9 \\
Toray Kevlar ${ }^{\oplus}$ fabric: FS3300 & & \\
\hline
\end{tabular}




\section{SS400 deck plate specimen}

Figure 5 shows the deck plate made of SS400 (hereafter referred to as the deck plate) used in this study. In this study, galvanized SS400 was used. As previously described, for an unprocessed SS400 steel plate, a thickness of at least $2.55 \mathrm{~mm}$ is required to prevent damage from impact with an energy of $9 \mathrm{~kJ}$. However, we used a 2.3mm-thick plate $(2.34-2.35 \mathrm{~mm})$ for this experiment because the flexural strength is increased through workhardening by changing the cross section into a trapezoidal corrugated shape. The plate was cut to dimensions of $750 \mathrm{~mm}$ (length) $\times 570 \mathrm{~mm}$ (width) to fit the fixing frame of the impact test equipment.

Permanent steel shelters should be integrated into the natural environment. Hence, we covered the exterior of the steel shelter with stones (pumice), sandbags, and plants to make it blend into the landscape. For the impact experiment, artificial pumice (hereafter referred to as pumice), with a composition and a specific gravity similar to those of natural pumice, in sandbags was placed in front of the specimen, as shown in Fig. 6. The

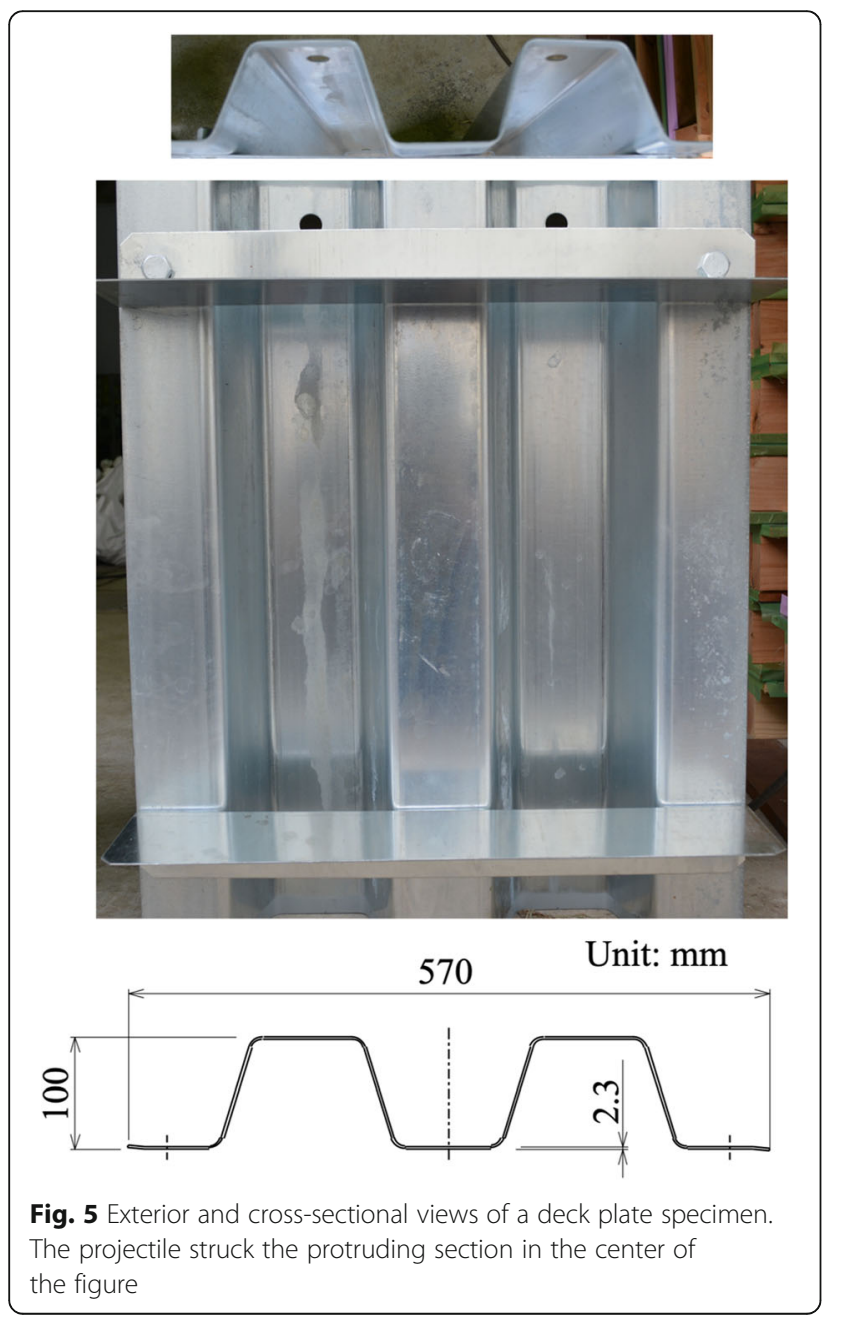

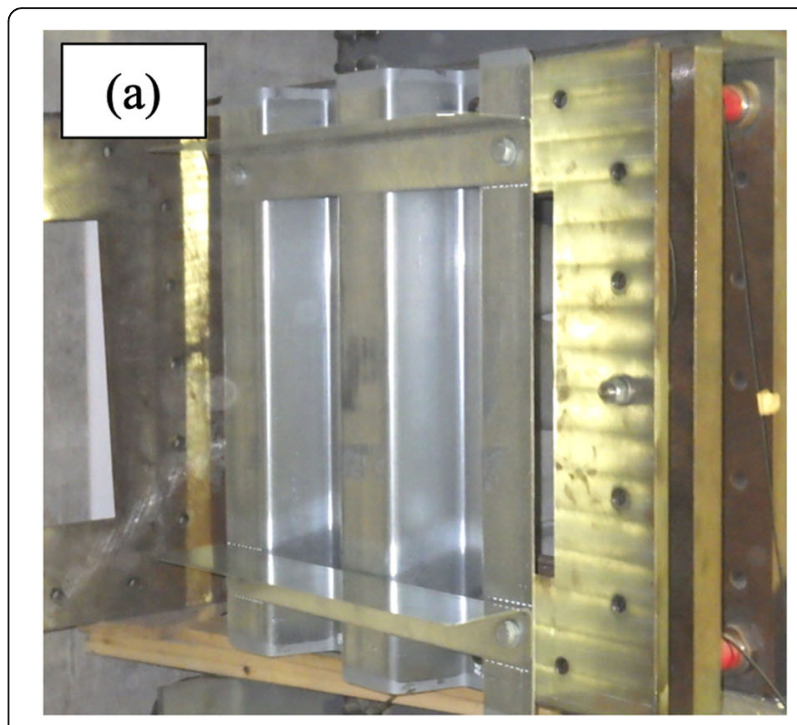

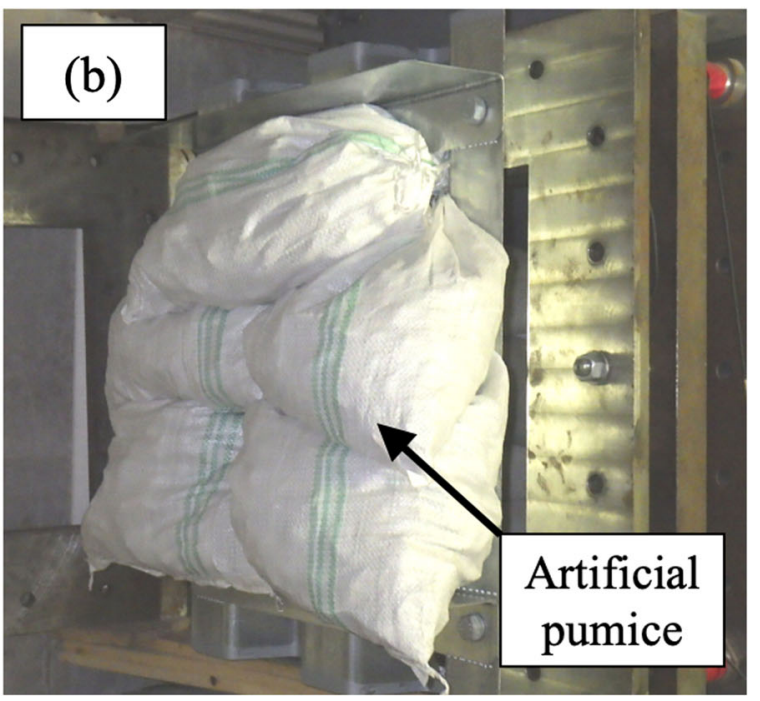

Fig. 6 Installation of the deck plate specimen on the fixing frame. a Before installation of artificial pumice (basic specimen) and (b) after installation of artificial pumice (pumice-containing specimen)

sandbag containing pumice is approximately $180 \mathrm{~mm}$ thick. The pumice used in this study was an inorganic porous material made from $96 \%$ waste glass. Its particle size was approximately 2 to $75 \mathrm{~mm}$ and its shape was irregular. The density in oven-dry conditions was between 300 and $600 \mathrm{~kg} / \mathrm{m}^{3}$. The quantitative effect should be examined by evaluating the strength of the pumice. However, this study is limited to qualitative comparisons of specimens with and without pumice. Specimens without pumice are referred to as basic specimens and those with pumice are referred to as pumice-containing specimens.

\section{Simulated ballistic ejecta impact test}

As in a previous study (Yamada et al. 2018), impact tests were carried out using a pneumatic impact test 
apparatus. In the previous study, the specimen was fixed between steel frames during the impact test on a simulated roof specimen. In the present study, the deck plate specimen was fixed directly to the frame using bolts. The projectile impacted the protruding section at the center of the deck plate specimen. The state of impact was recorded from the side using a high-speed camera (nac Image Technology, MEMRECAM Q1v) at 8000 frames per second with a 640 (horizontal) $\times 480$ (vertical) resolution.

\section{Experimental results and discussion Basic specimen}

Items 1 to 4 in Table 4 are the results of the simulated ballistic ejecta impact tests for the basic specimen. Even for the fastest impact (No. 4, energy of approximately $13.5 \mathrm{~kJ})$, the projectile did not penetrate the basic specimen. As shown in Fig. 4, withstanding an impact of about $7.5 \mathrm{~kJ}$ is the limit for a 2.3 -mm-thick SS400 unprocessed plate. Unlike the deformation mechanism for artillery shells (e.g., Corbett et al. 1996; Børvik et al. 1999) and space debris (e.g., Liou and Johnson 2006) that of volcanic ejecta, which travel slower, can be considered to be dominated primarily by bending deformation. Thus, increasing the flexural strength of the deck plate structurally has a considerable effect.

Figure 7a shows the state of deformation for specimen No. 4 after the impact test and the recovered simulated ballistic ejecta projectile. It can be seen that the projectile impacts almost straight with the central projection. A combination of buckling deformation and bending deformation appears near the impact region. This indicates that larger plastic deformation is induced around the impact region compared to that for the plate specimen. In addition, specimen No. 4 deformed plastically as a whole, which contributed to the large impact energy absorption. The projectile was severely fractured. Some of projectile fragments fell apart and could not be recovered. Figure $7 \mathrm{~b}$ shows the state of deformation for specimen No. 1 after the impact test and the recovered simulated ballistic ejecta projectile. When the impact energy decreases compared to specimen No. 4, the deformation is mainly in the impact region and the overall deformation is smaller than that for specimen No. 4. The simulated ballistic ejecta projectile had a slightly chipped edge; it did not exhibit the large fracture shown in Fig. 7b. Therefore, the strength of the ballistic ejecta projectile affects how energy is transferred into the target. In previous studies (Yamada et al. 2018; Yamada et al. 2019), the strength of the ballistic ejecta was not examined. It should be considered in a future study. The above experimental results show that considering both the mechanical and structural properties of materials can lead to stronger and lighter shelters.

\section{Pumice-containing specimen}

Items 5 to 9 in Table 4 are the results of the simulated ballistic ejecta impact tests for the pumice-containing specimens. Because part of the pneumatic impact test apparatus was damaged during the testing of a basic specimen (No. 4), we conducted an impact experiment at approximately $90 \mathrm{~m} / \mathrm{s}$ or less for safety reasons. The results of items 5 to 9 in Table 4 show that the projectile did not penetrate the pumice-containing specimens.

An example of the state of projectile impact on the pumice and deck plate specimen taken with the highspeed camera for specimen No. 8 is shown in Fig. 8 . After impacting the pumice, the projectile immediately impacted the deck plate, deformed it (see bulging at the extreme right (back of the specimen) after $0.023 \mathrm{~s}$ in Fig. 8 ), and then finally bounced away without penetrating. The video data indicate that there was no significant decrease in projectile speed even after the projectile hit the sandbag filled with pumice, which shows that the projectile was buried within the sandbag. Therefore, the impact deformation states of the basic and pumicecontaining specimens obtained at similar projectile speeds were compared. Figure 9 shows the deformation state of basic (No. 2) and pumice-containing specimens (No. 7) after the impact test. With or without pumice,

Table 4 Results of simulated ballistic ejecta impact tests on SS400 deck plate with and without pumice

\begin{tabular}{lllll}
\hline No. & Type of specimen & Impact velocity $(\mathbf{m} / \mathbf{s})$ & Impact energy $(\mathbf{k})$ & Result \\
\hline 1 & Without pumice & 64 & 5.4 & Deformed but not penetrated \\
2 & (Basic specimen) & 86 & 9.8 \\
3 & & 90 & 10.6 \\
4 & 101 & 13.5 \\
5 & With pumice & 83 & 9.2 \\
6 & (pumice-containing specimen) & 84 & 9.4 \\
7 & & 87 & 10.1 \\
8 & 91 & 11.0 \\
9 & 91 & 11.0 \\
\hline
\end{tabular}



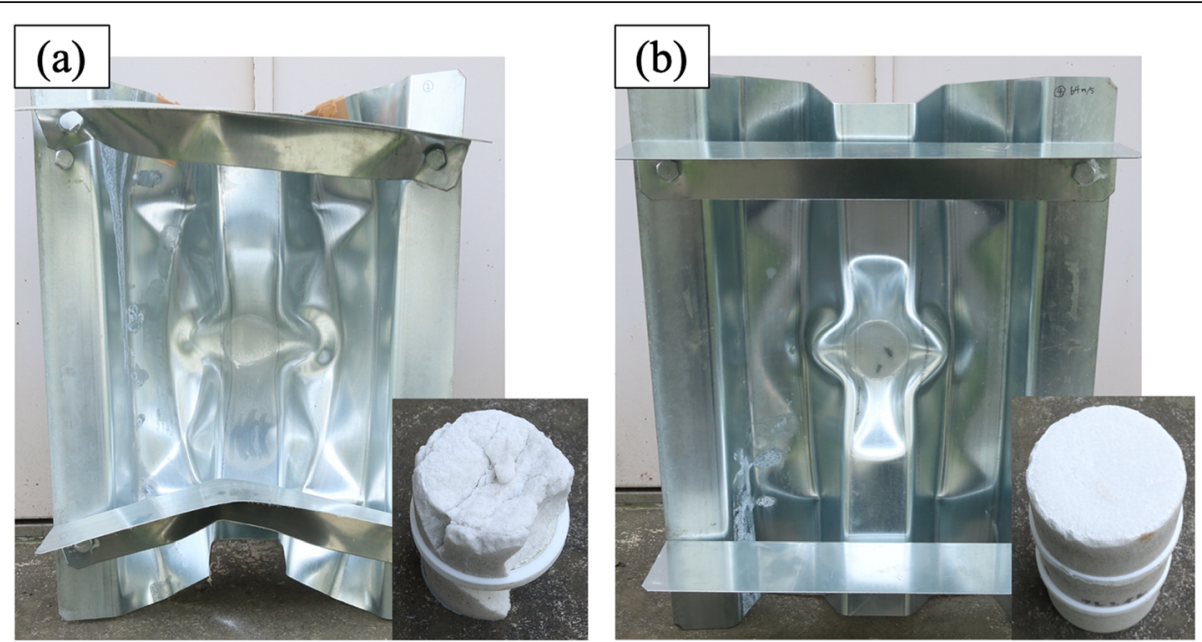

Fig. 7 State of deformation of basic specimen after impact test and the recovered simulated ballistic ejecta projectile for specimens (a) No. 4 $(13.5 \mathrm{~kJ})$ and (b) No. $1(5.4 \mathrm{~kJ})$

the projectile impacted at almost normal incidence the protruding section at the center of the specimen. Although it is difficult to show a quantitative difference, clear impact marks (arrows in Fig. 9) can be seen on the basic specimen but not on the pumice-containing specimen. As shown in Fig. 10, there was hardly any loss of energy due to projectile deformation or fracture in this experiment because the projectiles after impact showed almost no chipping or damage for the pumicecontaining specimen.

In order to quantitatively evaluate the impact absorption effect of pumice, the impact test on roof-simulating structure was performed. Originally, the effect of pumice should be examined on a 2.3-mm-thick SS400, but the

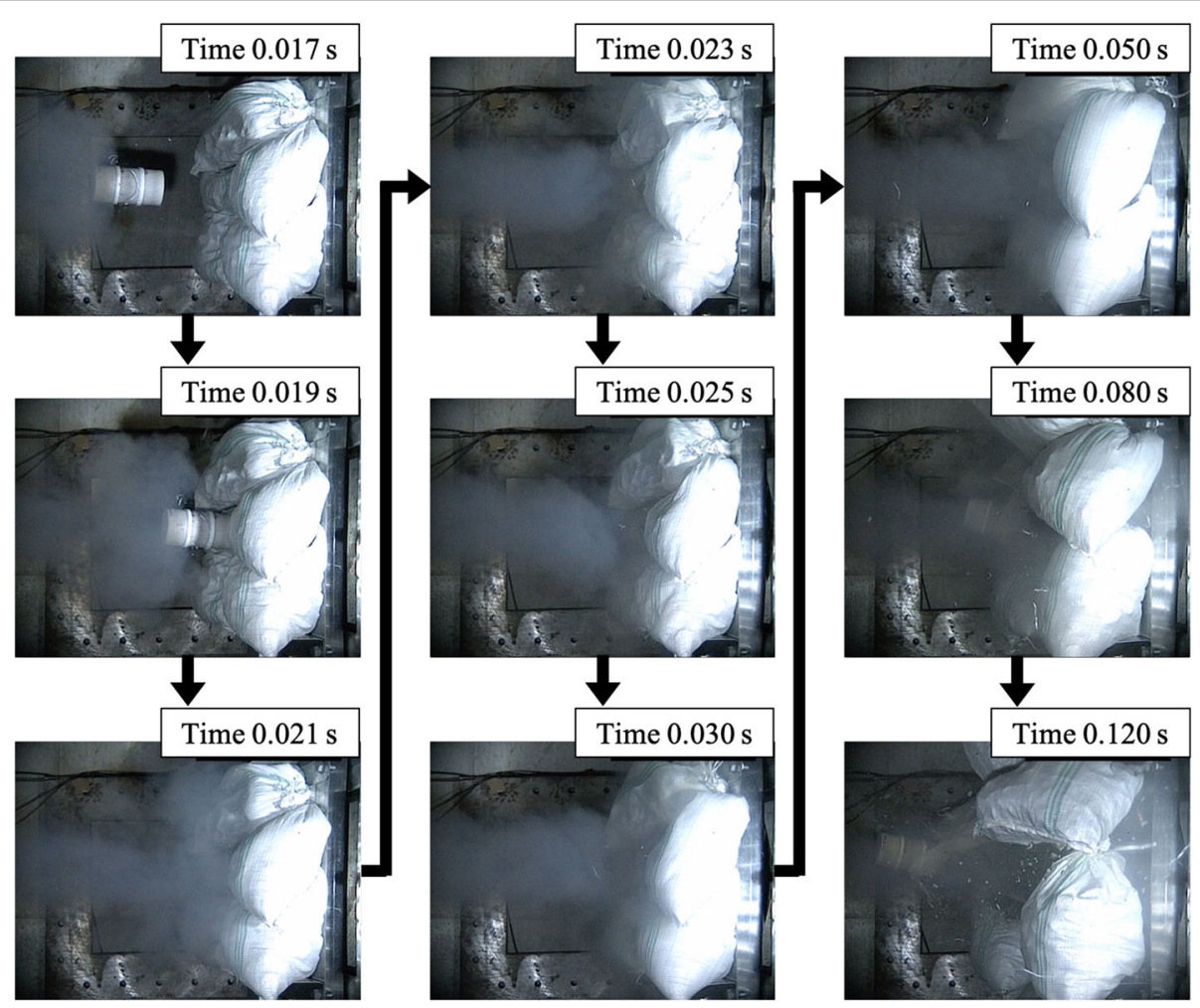

Fig. 8 State of impact of the projectile on the pumice and deck plate specimen taken with a high-speed camera specimen No. 8. The camera trigger start time was set to $0 \mathrm{~s}$ 

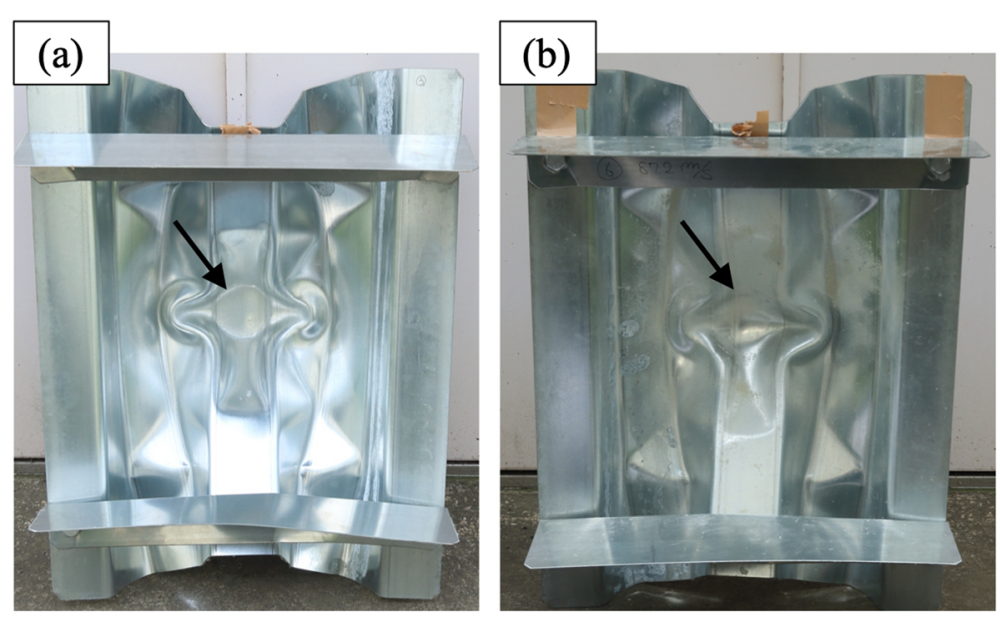

Fig. 9 State of deformation of (a) basic (No. 2) and (b) pumice-containing specimens (No. 7) after the impact test. The arrows indicate the impact marks. The installation of artificial pumice affected the shape of the impact mark

impact absorption effect of that could exceed the limit of the test apparatus. Therefore, we decided to use the wooden roof-simulating structure. This structure is Japanese cedar (Tenryu, Hamamatsu, Shizuoka Prefecture, Japan) with a thickness of $15 \mathrm{~mm}$ as roofboard installed on the surface waterproof sheet and $0.4 \mathrm{~mm}$ thick Galvalume $^{\circ}$ steel sheet (55\% aluminum-zinc alloy steel sheet; hereafter "Galvalume steel sheet") but also one having an additional rafter installed (for details, see Yamada, et al. (2018)). In the roof-simulating structure, it was clear that the boundary between penetrating and nonpenetrating impact energy was taken to be near $1.2 \mathrm{~kJ}$ (Yamada et al. 2018). Similar to the pumice-containing specimen, the sandbag containing pumice (approximately $180 \mathrm{~mm}$ thick) was installed on the roofsimulating structure and an impact test was conducted. Table 5 shows the results of the simulated ballistic ejecta impact tests on roof-simulating structure with pumice. Due to the installation of pumice, the boundary between penetrating and non-penetrating impact energy was taken to be near $3.7 \mathrm{~kJ}$. Therefore, the impact absorption energy of pumice used in this study can be calculated as approximately $2.5 \mathrm{~kJ}$. Note that this value varies greatly depending on the material type and thickness. In addition, the above result reflects the effect of the installation of pumice on the roof-simulating structure. Therefore, even if the pumice is placed on steel materials, the same impact absorption energy is not always obtained. However, since the effect was shown with the roof-simulating structure that is weaker than the steel material, there is no doubt that the impact absorption energy will be improved by the installation of pumice on the steel material.

Therefore, the effect of installing artificial pumice was confirmed. For actual shelters, pumice is useful in terms of increasing strength as well as improving appearance (i.e., making a shelter blend into the surroundings). Another noteworthy point is that pumice could prevent ejecta from fragmenting on impact (Williams et al. 2019) and thereby make people less likely to be struck by

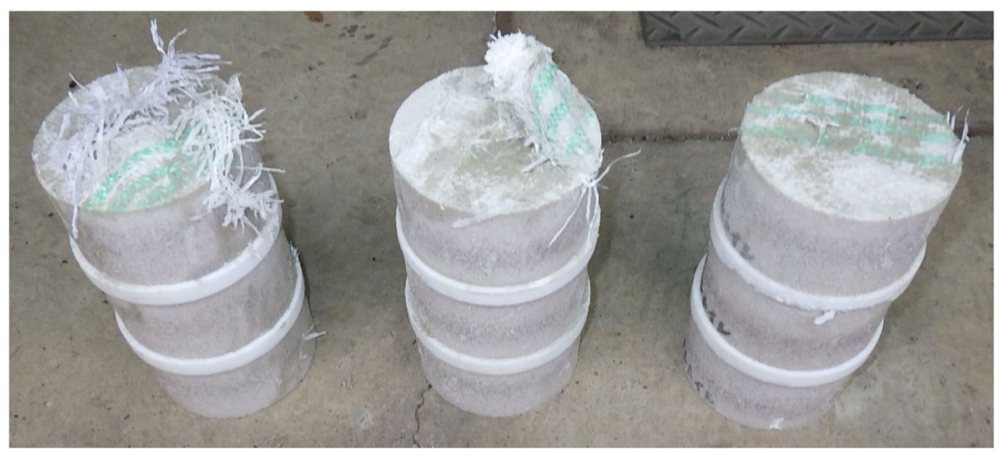

Fig. 10 External appearance of projectiles after impact tests (from left to right, No. 8, No. 5, and No. 9) 
Table 5 Results of simulated ballistic ejecta impact tests on roof-simulating structure with pumice. For the roof-simulating structure without pumice, the boundary between penetrating and non-penetrating impact energy was taken to be near $1.2 \mathrm{~kJ}$ (Yamada et al. 2018)

\begin{tabular}{lllll}
\hline No. & Type of specimen & Impact velocity $(\mathbf{m} / \mathbf{s})$ & Impact energy $(\mathbf{k})$ & Result \\
\hline 1 & Roof-simulating structure with pumice & 52 & 3.6 & Deformed but not penetrated \\
2 & (Japanese cedar with a thickness of $15 \mathrm{~mm})$ & 53 & 3.8 & Penetrated \\
3 & & 54 & 3.9 & \\
4 & & 55 & 4.0 & \\
\hline
\end{tabular}

fragments. It can be said that the effect of reinforcements such as pumice is important for the installation of shelters at active volcanoes.

\section{Example of shelter using deck plates}

Figure 11 shows an example of a steel shelter built using SS400 deck plates (Toko Tekko Co., Ltd.), and installed near the Otaki Chojo Sanso hut on Mt. Ontake (b). These plates are capable of preventing damage caused by an impact energy of $13.5 \mathrm{~kJ}$ and more. Cold forming using the bending process was performed on the SS400 deck plate to process it into an arc shape. Two of these processed plates were then assembled and connected with bolts at the top to make an arched shelter. Because the flexural rigidity of the deck plate is very high, it is possible to make a self-standing structure without structural columns. This shelter can be designed to match the characteristics of a specific volcano region such as uneven and steep terrain. By making one unit of the shelter small enough to meet transportation requirements, the shelter can be prefabricated, transported, and assembled on site. A similar shelter used at Showa Station in Antarctica has been able to withstand the polar environment, including outdoor temperatures of below $-40{ }^{\circ} \mathrm{C}$ and blizzards with maximum instantaneous wind speeds of over $60 \mathrm{~m} / \mathrm{s}$ (Genshiryoku Sangyo Shimbun 2018). Hence, the shelter can be installed permanently and survive the winter, even at altitudes of 2000 to 3000 m. In this study, the material was galvanized to prevent rusting; the long-term corrosion resistance to volcanic gases was not examined. A study on durable coatings and their resistance to volcanic gases should thus be carried out. In addition, processing 2.3-mm-thick plates is the limit given the current technology. Developments in processing technology will improve the shelter.

\section{Conclusions}

The most effective safety measures against volcanic ballistic hazards are the designation of restricted access areas. On the other hand, the damage and casualties caused by the Mt. Ontake eruption in 2014 highlighted the need for better evacuation facilities that are suitable for the target location especially in cases of unheralded phreatic eruptions. Accordingly, in this study, we proposed the use of easily available and relatively inexpensive steel materials for building shelters. Assuming that the impact energy of ballistic ejecta is $9 \mathrm{~kJ}$ and more, as was done in previous studies, we first considered a method for reinforcing wooden buildings using SUS304 and SS400 unprocessed steel plates to withstand impacts with this energy. Without using previously proposed aramid fabric, we focused on workability and material price and demonstrated that it is possible to reinforce mountain huts relatively inexpensively by using SUS304.

SUS304 is suitable for use as a reinforcing material because it has excellent impact energy absorption due to
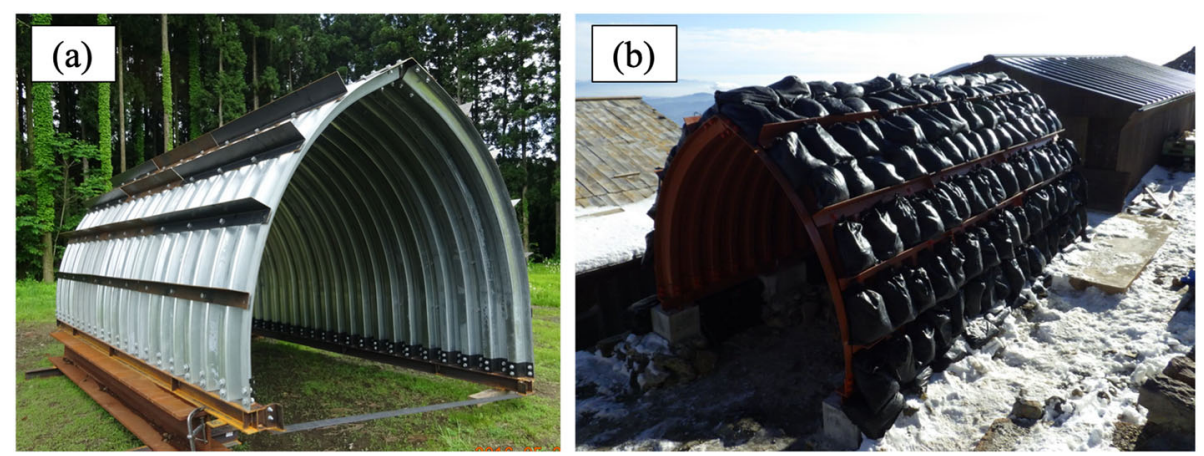

Fig. 11 a An example of a steel shelter built using deck plates (Toko Tekko Co., Ltd.). b This is installed near the Otaki Chojo Sanso hut on Mt. Ontake. Photograph taken by Mr. Hieda in 2019. Impact resistance to ballistic ejecta may be further improved by installing sandbags with high shock-absorbing resistance on the surface 
its high ductility, as well as excellent corrosion resistance. However, the construction cost with light aramid fabrics is lower than that with SUS304 in high-altitude mountain huts. It is thus necessary to take the transportation and construction cost of materials into account. The material and construction method should be suitable for the target environment. If there are no restrictions on the construction requirements and cost, RC shelters provide the best impact resistance to ballistic ejecta. Nevertheless, the results of this study can be used to select a reinforcement method that best matches location restrictions.

To increase the structural strength of steel shelters, we also conducted an impact experiment on a shelter using galvanized SS400 deck plates loaded with pumice. The results showed that the shelter could withstand impact with an energy of $13.5 \mathrm{~kJ}$ and more. Because there is still some allowance for deformation caused by projectile impact, this steel shelter holds promise, not only structurally, but also from the aspects of transportation and assembly.

In future studies, it will be necessary to consider how the corrosion resistance and mechanical properties of SUS304 and galvanized SS400 can be maximized in environments exposed to corrosive volcanic gases. By aiming for the construction of maintenance-free evacuation facilities and shelters with good corrosion resistance, we hope to help reduce the installation and maintenance costs associated with ballistic ejecta shelters.

\section{Acknowledgements}

Information on aramid fiber reinforcement construction was kindly provided by Toray Industries, Inc. and Teijin Frontier Co., Ltd. Additionally, nac Image Technology kindly assisted us with the high-speed camera shooting. The photograph of the steel shelter near the hut on Mt. Ontake was obtained in cooperation with Mr. Hieda from Otaki Village, Mr. Wade from Kiso Town, and a member of Takizawa Koumuten Co., Ltd. We would like to take this opportunity to express our deep appreciation.

\section{Authors' contributions}

HY planned the research and prepared the manuscript. KT summarized the entire impcat test using a pneumatic impact test apparatus. SN and HS conducted a survey on the current status of shelters in Japan and assisted in the impact tests. ST prepared deck plate specimens and conducted the impact tests. RH, TK, MY and TF performed the impact tests. The authors read and approved the final manuscript.

\section{Funding}

This project was supported by JSPS KAKENHI Grant Number JP16H03148.

\section{Availability of data and materials}

The datasets used and/or analyzed during the current study are available from the corresponding author on reasonable request.

\section{Declarations}

\section{Competing interests}

The authors declare that they have no competing interests.

\section{Author details}

1 Department of Mechanical Engineering, National Defense Academy,

1-10-20, Hashirimizu, Yokosuka, Kanagawa 239-8686, Japan. ${ }^{2}$ Department of
Mechanical Engineering, Ritsumeikan University, 1-1-1 Noji-higashi, Kusatsu, Shiga 525-8577, Japan. ${ }^{3}$ Asia Air Survey Co., Ltd., Shinyuri 21 Building, 1-2-2 Manpukuji, Asao-ku, Kawasaki, Kanagawa 215-0004, Japan. ${ }^{4}$ Toko Tekko Co., Ltd., 19-1 Inariyamashita, Shakanai, Odate, Akita 017-0012, Japan. ${ }^{5}$ Mount Fuji Research Institute, Yamanashi Prefectural Government, 5597-1 Kenmarubi, Kamiyoshida, Fujiyoshida, Yamanashi 403-0005, Japan.

Received: 13 August 2020 Accepted: 24 May 2021

Published online: 21 June 2021

\section{References}

Baxter P, Gresham AC (1997) Deaths and injuries in the eruption of Galeras Volcano, Colombia, 14 January 1993. J Volcanol Geotherm Res 77:325-338. https://doi.org/10.1016/S0377-0273(96)00103-5

Beppu M, Miwa K, Takahashi J (2012) Failure mechanism of the scabbing of concrete plates subjected to high velocity impact and effects of fiber sheet reinforcement. J Jpn Soc Civ Eng 68:398-412. https://doi.org/10.2208/ jscejseee.68.398 (in Japanese)

Bhatti AQ (2015) Falling-weight impact response for prototype RC type rock-shed with sand cushion. Mater Struct 48:3367-3375. https://doi.org/10.1617/s1152 7-014-0405-5

Bhatti AQ, Kishi N (2010) Impact response of RC rock-shed girder with sand cushion under falling load. Nucl Eng Design 240:2626-2632. https://doi.org/1 0.1016/j.nucengdes.2010.07.029

Børvik T, Langseth M, Hopperstad OS, Malo KA (1999) Ballistic penetration of steel plates. Inter J Impact Eng 22:855-886. https://doi.org/10.1016/S0734-743 $X(99) 00011-1$

Breard ECP, Lube G, Cronin SJ, Fitzgerald R, Kennedy B, Scheu B, Montanaro C, White JDL, Tost M, Procter JN, Moebis A (2014) Using the spatial distribution and lithology of ballistic blocks to interpret eruption sequence and dynamics: August 62012 Upper Te Maari eruption, New Zealand. J Volcanol Geotherm Res 286:373-386. https://doi.org/10.1016/j.jvolgeores.2014.03.006

Chiba N, Shida S, Ohte S, Yoshizawa H (1981) Impact strength of steel plates struck by projectiles: 1st report, thickness dependence of the critical fracture energy of the plates. Trans Jpn Soc Mech Eng 47:1101-1109. https://doi. org/10.1299/kikaia.47.1101 (in Japanese)

Corbett GG, Reid SR, Johnson W (1996) Impact loading of plates and shells by free-flying projectiles: a review. Inter J Impact Eng 18:141-230. https://doi. org/10.1016/0734-743X(95)00023-4

Disaster Management, Cabinet Office (2015a) Handbook for improving the volcanic shelter. http://www.bousai.go.jp/kazan/shiryo/pdf/201512_hinan_ tebiki3.pdf (in Japanese) Accessed 13 Aug 2020

Disaster Management, Cabinet Office (2015b) Handbook for improving the volcanic shelter (reference material). http://www.bousai.go.jp/kazan/shiryo/ pdf/201512_hinan_tebiki4.pdf (in Japanese) Accessed 13 Aug 2020

Erfurt-Cooper P (2010) Volcano and geothermal tourism in Kyushu, Japan. Volcano Geotherm Tour. https://doi.org/10.4324/9781849775182

Fitzgerald RH, Kennedy BM, Wilson TM, Leonard GS, Tsunematsu K, Keys H (2017) The communication and risk management of volcanic ballistic hazards. In: Fearnley CJ, Bird DK, Haynes K, McGuire WJ, Jolly G (eds) Observing the volcano world. Advances in volcanology (an official book series of the International Association of Volcanology and Chemistry of the Earth's interior - IAVCEI, Barcelona, Spain). Springer, Cham, pp 121-147

Fitzgerald RH, Tsunematsu K, Kennedy BM, Breard ECP, Lube G, Wilson TM, Jolly AD, Pawson J, Rosenberg MD, Cronin SJ (2014) The application of a calibrated 3D ballistic trajectory model to ballistic hazard assessments at Upper Te Maari, Tongariro. J Volcanol Geotherm Res 286:248-262. https://doi. org/10.1016/j.jvolgeores.2014.04.006

Fukui T, Sato M, Yamada H, Kitajima T, Ogasawara N, Yui A (2017) Study on wheel cover safety for grinding machines: collision experiments for stainless steel covers. J J.jn Soc Abrasive Tech 61:93-98. https://doi.org/10.11420/jsat.61.93 (in Japanese)

Genshiryoku Sangyo Shimbun (2018) Provide diverse products that can withstand harsh environments with technology and spirit cultivated in the mining business. Japan Atomic Industrial Forum, Inc. https://www.jaifor.jp/1 80516-2 (in Japanese) Accessed 13 Aug.

Hopkinson B (1914) A method of measuring the pressure in the deformation of high explosives by the impact of bullets. Phil Trans Roy Soc 213:437-452. https://doi.org/10.1098/rsta.1914.0010

Hughes G (1984) Hard missile impact on reinforced concrete. Nucl Eng Design 77:23-25. https://doi.org/10.1016/0029-5493(84)90058-X 
Ito C, Ohnuma H, Shirai K (1991) Design method of concrete structures against impact due to collision of missile. CRIEPI Res Rep U24:1-141 (in Japanese)

Ito C, Shirai K, Ohnuma H (1995) Design formula of reinforced concrete structures against rigid missile impact. Doboku Gakkai Ronbunshu 507:201-208. https:// doi.org/10.2208/jscej.1995.507_201 (in Japanese)

Izumo S, Sueyoshi H, Kitamura K, Ohzono Y (1990) Corrosion of metals in volcanic atmosphere. Corros Eng 39:247-253. https://doi.org/10.3323/jcorr1 974.39.5_247 (in Japanese)

Japan Metal Roofing Association, Japanese Society of Steel Construction, 2014. Manual on design, construction and maintenance for steel roofing and wall. (in Japanese)

Kanagawa Shimbun (2018) Beware of "ballistic ejecta" Lessons from KusatsuShirane and Ontake volcanoes. Kanagawa Shimbun. https://www.kanaloco.jp/ news/social/entry-25499.html (in Japanese) Accessed 13 Aug.

Kaneko T, Maeno F, Nakada S (2016) 2014 mount Ontake eruption: characteristics of the phreatic eruption as inferred from aerial observations. Earth Planets Space 68:72. https://doi.org/10.1186/s40623-016-0452-y

Kolsky $H$ (1949) An investigation of the mechanical properties of materials at very high rates of loading. Proc Phys Soc 62:676-700. https://doi.org/10.1088/03 70-1301/62/11/302

Kpenyigba KM, Jankowiak T, Rusinek A, Pesci R (2013) Influence of projectile shape on dynamic behavior of steel sheet subjected to impact and perforation. Thin Walled Struct 65:93-104. https://doi.org/10.1016/j.tws.2013. 01.003

Liou J-C, Johnson NL (2006) Risks in space from orbiting debris. Science 311:340341. https://doi.org/10.1126/science.1121337

Ohte S, Yoshizawa H, Chiba N, Shida S (1981) Impact strength of steel plates struck by projectiles: 2nd report, critical energy formula for steel plate fracture. Trans Jpn Soc Mech Eng 47:1373-1379. https://doi.org/10.1299/kika ia.47.1373 (in Japanese)

Oikawa T, Yamaoka K, Yoshimoto M, Nakada S, Takeshita Y, Maeno F, Ishizuka Y, Komori J, Nakano S (2015) The 2014 eruption of Ontake volcano, Central Japan. Bull Volc Soc Japan 60:411-415. https://doi.org/10.18940/kazan. 60.3_411 (in Japanese)

Oikawa T, Yoshimoto M, Nakada S, Maeno F, Komori J, Shimano T, Takeshita Y, Ishizuka Y, Ishimine $Y$ (2016) Reconstruction of the 2014 eruption sequence of Ontake volcano from recorded images and interviews. Earth Planets Space 68:79. https://doi.org/10.1186/s40623-016-0458-5

Oze C, Cole J, Scott A, Wilson T, Wilson G, Gaw S, Hampton S, Doyle C, Li Z (2014) Corrosion of metal roof materials related to volcanic ash interactions. Nat Hazards 71:785-802. https://doi.org/10.1007/s11069-013-0943-0

Terada A, Kanda W, Ogawa Y, Aoyama H, Yamamoto M, Tsutsui T, Ohkura T, Noguchi R (2018) The phreatic eruption on 23 January 2018 at Mt. MotoShirane of Kusatsu-Shirane volcano, Japan: geophysical observations and implications. Abstract J.jGU 2018, Chiba, pp SVC41-SVC37 (in Japanese)

Tsunematsu K, Ishimine Y, Kaneko T, Yohimoto M, Fujii T, Yamaoka K (2016) Estimation of ballistic block landing energy during 2014 Mount Ontake eruption. Earth Planets Space 68:88. https://doi.org/10.1186/s40623-016-04638.

Williams GT, Kennedy BM, Lallemant D, Wilson TM, Allen N, Scott A, Jenkins SF (2019) Tephra cushioning of ballistic impacts: Quantifying building vulnerability through pneumatic cannon experiments and multiple fragility curve fitting approaches. J Volcanol Geotherm Res 388:106711. https://doi. org/10.1016/j.jvolgeores.2019.106711

Williams GT, Kennedy BM, Wilson TM, Fitzgerald RH, Tsunematsu K, Teissier A (2017) Buildings vs. ballistics: quantifying the vulnerability of buildings to volcanic ballistic impacts using field studies and pneumatic cannon experiments. J Volcanol Geotherm Res 343:171-180. https://doi.org/10.1016/j. jvolgeores.2017.06.026

Yamada H, Sato M, Ogasawara N, Takayuki K, Yui A (2016) Collision test of abrasive projectiles against steel sheet using large-scale launching system. Adv Exp Mech 1:161-166. https://doi.org/10.11395/aem.1.0_161

Yamada H, Tateyama K, Honda R, Yoshimoto M, Fujii T (2019) Simple structural reinforcement of roof of wooden buildings subjected to ballistic Ejecta impact. Bull Volcanol Soc Japan 64:243-251. https://doi.org/10.18940/kazan. 64.4_243 (in Japanese)

Yamada H, Tateyama K, Sasaki H, Naruke S, Kisimoto H, Yoshimoto M (2018) Impact resistance to ballistic ejecta of wooden buildings and a simple reinforcement method using aramid fabric. J Volcanol Geotherm Res 359:3746. https://doi.org/10.1016/j.jvolgeores.2018.06.014
Yamaguchi S, Komuro M, Kurihashi Y, Konno H, Kishi N (2015) Full-scale impact tests of a rockfall protection gallery - cases using sand and gravel cushions. Kozo Kogaku Ronbunshu A 61A:1012-1023. https://doi.org/10.11532/ structcivil.61A.1012 (in Japanese)

Yoshimoto M (2015) Protecting yourself from ballistic ejecta: lessons of 2014 Mt. Ontake eruption. Volcanic Disaster Prevention Symp Text, Toyama, pp 18-21 http://www.kazan.or.jp/doc/2015kazanbosai_symposium_abst.pdf (in Japanese). Accessed 27 July 2020

Yoshimoto M, Honda R, Yasuda T, Ishimine Y, Yamada H, Komori J, Terada A, Hirabayashi J, Fujii T (2018) Preliminary report on damage caused by the ballistic block of the 2018 phreatic eruption of Kusatsu-Shirane volcano, abstract cities on volcanoes 10, Napoli, Italy

\section{Publisher's Note}

Springer Nature remains neutral with regard to jurisdictional claims in published maps and institutional affiliations.
Ready to submit your research? Choose BMC and benefit from:

- fast, convenient online submission

- thorough peer review by experienced researchers in your field

- rapid publication on acceptance

- support for research data, including large and complex data types

- gold Open Access which fosters wider collaboration and increased citations

- maximum visibility for your research: over $100 \mathrm{M}$ website views per year

At BMC, research is always in progress.

Learn more biomedcentral.com/submissions 